\title{
Results of laparoscopic resection in high- risk rectal cancer patients
}

\section{Authors:}

Sofoklis Panteleimonitis MRCS ${ }^{1,3}$, Nuno Figueiredo FRCS2, Thakshyanee Bhunakrishna MRCS $^{3}$, Mick Harper PhD ${ }^{1}$, Amjad Parvaiz FRCS ${ }^{1,2,3}$

\section{Affiliations:}

1. University of Portsmouth, School of Health and Care Professions, St Andrews Court, St Michael's road, Portsmouth, PO1 2PR, United Kingdom

2. Champalimaud Foundation, Av. Brasilia, 1400-038, Lisbon, Portugal

3. Poole Hospital NHS Trust, Longfleet road, Poole, BH15 2JB, United Kingdom

\section{Corresponding author:}

Mr Sofoklis Panteleimonitis

Phone: 00447721773383

Email: sofoklis_p@hotmail.com

ORCID ID: 0000-0003-3610-1201 


\section{Abstract}

Purpose:

Obesity, neoadjuvant-radiotherapy, tumour proximity to the anal verge and previous abdominal surgery are factors that might increase the intra-operative difficulty of laparoscopic rectal cancer surgery. However, whether patients with these 'high-risk' characteristics are subject to worse shortor long-term outcomes is debated. The aim of this study is to examine the short- and long-term clinical and oncological outcomes of patients receiving laparoscopic rectal surgery with any of these high-risk characteristics and compare them with patients that do not possess any of these high-risk features.

Methods:

For the purpose of this study data from consecutive patients receiving laparoscopic rectal cancer resections between 2006 and 2016 from two centres were analysed. High-risk patients were defined as patients with either one of the following characteristics: BMI $\geq 30$, neoadjuvantchemoradiotherapy, tumour $<8 \mathrm{~cm}$ from the anal verge and previous abdominal surgery.

Results:

313 patients were identified ( 227 high-risk, 86 low-risk). Short-term outcomes were similar between the two groups with the exception of blood loss and length of stay, which were higher in the high-risk group ( 10 vs $2.5 \mathrm{ml}, p=0.045 ; 7$ vs 5 days, $p=0.001$ ). There were no statistically significant differences in 5 -year overall survival $(79.7 \%$ vs $79.8 \%, p=0.757)$, disease-free-survival ( $76.8 \%$ vs $69.3 \%, p=0.175)$, distant disease-free interval ( $84.8 \%$ vs $79.7 \%, p=0.231)$ and local recurrence free interval $(100 \%$, $97.4 \%, p=0.162$ ) between the two groups.

Conclusion:

Similar short- and long-term outcomes can be achieved in high-risk and low-risk patients receiving laparoscopic rectal surgery. The presented data support the suitability of laparoscopic surgery for this group of patients.

\section{Key Words}

Minimally invasive surgery, laparoscopy, rectal cancer, high risk 


\section{Authors Contributions}

Sofoklis Panteleimonitis: study conception and design, acquisition of data, analysis and interpretation of data, drafting of manuscript.

Nuno Figueiredo: acquisition of data, critical revision of manuscript.

Mick Harper: critical revision of manuscript.

Thakshyanee Bhunakrishna: acquisition of data, drafting of manuscript.

Amjad Parvaiz: study conception and design, acquisition of data, critical revision of manuscript. 


\section{Introduction}

Laparoscopic surgery has become the "gold standard" for colorectal resections in the developed world with its benefits such as shorter hospital stay, less postoperative pain, early mobilisation and improved cosmesis being well established [1-6]. Two recent randomised control trials (ACOSOG Z6051 [7] and ALaCaRT [8]) examining the role of minimally invasive surgery (MIS) in rectal cancer resections have raised questions as to oncological equivalency to open surgery. Nevertheless, equivalence is supported as similar local-recurrence rates and disease-free survival have been documented on long-term follow-up [9, 10]. However, it remains uncertain if sub-groups of patients considered "high-risk", such as those with a high body mass index (BMI), those receiving neo-adjuvant radiotherapy or in patients with low-lying tumours are at risk of receiving sub-optimal resections when submitted to MIS [8].

Patient characteristics associated with intra-operative difficulty and categorising surgery as high-risk are often reported in the literature [11-24]. Several studies have demonstrated that obesity can lead to inferior short-term outcomes in laparoscopic colorectal surgery [11,12,17], although this is still contested in other studies $[18,19]$. Neo-adjuvant radiotherapy has led to reduced locoregional recurrence rates and as a result its increased application in rectal cancer treatment. However, these patients can represent a surgical challenge since the relative ischaemia after irradiation tends to make the tissues oedematous and friable, often increasing intra-operative bleeding and morbidity [20-24]. Additionally, prior abdominal surgery and tumours close to the anal verge have been cited as risk factors for conversion and surgical morbidity [13-16]. Therefore, it is contested that patients with these characteristics are in high-risk of having worse short-term clinical and pathological outcomes and possibly even worse long-term oncological outcomes.

Although the above risk factors have been investigated in the literature independently, there are only a few studies examining the clinical and pathological outcomes of high-risk patients in minimally invasive colorectal resections, with any number of the above risk factors [25-27]. This study aims to analyse and compare the short and long-term outcomes of high-risk and low-risk patients receiving laparoscopic rectal cancer surgery by a standardised modular approach to enable a baseline of evidence to be used as a foundation for further investigation. 


\section{Material and methods}

Consecutive rectal cancer patients from two centres, one from the UK and one from Portugal, who received laparoscopic resections between 2006 and 2016 were identified from prospectively collected databases. The inclusion criteria included all patients receiving laparoscopic rectal cancer resections, regardless of whether they were converted to open surgery or not. Exclusion criteria included open surgery and surgery for benign disease.

Patients were stratified to high-risk or low-risk according to set criteria. High-risk patients were defined as patients with either one of the following characteristics: obese (BMI of $\geq 30$ ), neoadjuvant radiotherapy, tumour $<8 \mathrm{~cm}$ from the anal verge and previous abdominal surgery. Patients with none of the above characteristics were defined as low-risk patients. The short-term surgical and long-term survival outcomes of the high-risk and low-risk patients were analysed.

All patients with a histologically confirmed rectal adenocarcinoma were discussed in the local multidisciplinary team meeting (MDT) before commencing any treatment. Rectum was defined as a distance of $15 \mathrm{~cm}$ from the anal verge on MRI scan. In general, neo-adjuvant chemoradiotherapy was given to patients with a threatened circumferential resection margin $\leq 2 \mathrm{~mm}$ or T4 in staging on MRI, and not used where rectal cancers were considered resectable by total mesorectal excision (TME) with a likelihood of clear margins.

Laparoscopy was the default approach for all patients with surgeries either performed or closely supervised by two consultant surgeons. Contra-indications to laparoscopy were patients not deemed anaesthetically fit to tolerate pneumoperitoneum and patients requiring multi-visceral resections. All patients with significant co-morbidities $(A S A>3)$ underwent cardiopulmonary exercise testing by our anaesthetic department pre-operatively in order to assess their fitness for surgery. On this basis, three patients were excluded from receiving a curative resection as their primary treatment and received chemoradiotherapy instead.

Two laparoscopic colorectal surgeons performed or closely supervised all procedures in each unit. Data collection began when the surgeons participating in this study started working in their respective units, in 2006 for the UK centre and 2013 for the Portuguese centre. Surgeon A trained surgeon B in laparoscopic colorectal surgery and therefore both surgeons applied a modular, standardised previously described approach to surgery [28-30].

Post-operative care was standardised and patients entered an enhanced recovery programme based on the one described by Kehlet and Wilmore [31], with the only exception being the selective use of epidural catheters for pain relief. Patients were discharged home when assessed as meeting set 
criteria for discharge. Patients were followed up 6 weeks following their surgery and had subsequent 6-monthly follow up appointments for the first 2 years and further annual clinic appointments up to 5 years. The colon was examined at the $2^{\text {nd }}$ and $5^{\text {th }}$ year following surgery. CT scans of the chest, abdomen and pelvis were performed on an annual basis for first 3 years and at 5 years.

All recruited patients signed an informed consent form allowing their data to be used for analysis and its publishing. The requirements for anonymization of personal dataset by the Data Protection Act 1998 were satisfied. According to the Health Research Authority (HRA), this study was not classified to need their approval as it is an audit.

\section{Surgical technique}

All procedures were performed through a well-established, previously described, standardised modular technique $[28,32]$. This approach permits a safe and reproducible technique that also facilitates teaching and training [29].

The patients were placed in the modified Lloyd Davies position. The optical port was placed infraumbilical in the midline with the open Hassan technique and pneumoperitoneum was established. Pressure was set to $12 \mathrm{mmHg}$. Further ports were inserted under direct vision at the right iliac fossa, right upper quadrant and left upper quadrant as demonstrated in a previously published video article [33]. Procedures commenced with medial to lateral dissection followed by vascular control by ligating the main vessels. Hem-o-lok's were used to secure the vessels before division and a three step approach was used for splenic mobilisation [34]. These included: 1) medial to lateral dissection towards and above the pancreas, 2) lateral colonic mobilisation and 3) separation of omentum from transverse colon. TME started with posterior mobilization followed by right lateral, anterior and left lateral mobilisation in a stepwise manner. Dissection was performed by monopolar diathermy. All patients receiving complete TME surgery were given pre-operative bowel preparation the day before surgery and had loop ileostomies fashioned in cases where an anastomosis was formed.

\section{Data collection and outcome assessment}

All data was retrospectively collected from prospectively collated databases. Baseline characteristics analysed were age, gender, body mass index (BMI), American Society of Anaesthesiologists (ASA) grade, operating surgeon, previous abdominal surgery (defined as any patients with previous open abdominal surgery which involved bowel manipulation or resection, these operations included any open bowel resection, appendicectomy and hysterectomy), tumour distance from the anal verge, neoadjuvant radiotherapy, operation performed tumour (T) stage (pathological T stage was used) and American Joint Committee on Cancer (AJCC) stage. Short-term outcomes examined included 
operative time, estimated blood loss (EBL), conversion to open (defined as any incision needed to either mobilise the colon or rectum or ligate the vessels), length of stay (LOS), 30-day readmission, 30day reoperation, 30-day mortality, clinical anastomotic leak, lymph node yield and circumferential resection margin (CRM) clearance. Long-term outcomes investigated included 5-year overall survival (OS), disease free survival (DFS), distant disease-free interval and local recurrence free interval. Distant-disease and local recurrence free intervals specifically investigate the time to distant or local disease recurrence respectively and do not account for deaths [35]. Distant recurrence was defined as any evidence on imaging of metastatic disease in a new site. Local recurrence was defined as any evidence on imaging or endoscopy of disease in the pelvis or anastomotic site. Any of these findings led to an MDT discussion to confirm this. Survival and disease recurrence status were checked on a regular basis from all electronic records by a designated data manager and updated on the databases.

\section{Statistical analysis}

Data analysis was performed using IBM SPSS version 24 (SPSS Inc., Chicago, IL, USA). Non-parametric data was expressed as median with interquartile range and parametric data as mean with standard deviation. Cohort demographic and clinical characteristics were compared using $\chi^{2}$ test or Fishers exact test for categorical variables, Mann-Whitney $\mathrm{U}$ test for non-parametric continuous variables and $t$ test for parametric continuous variables. $P$ values of $<0.05$ were considered statistically significant.

A univariate and multivariate binary logistic regression model was applied to investigate whether being a high-risk patient affected morbidity and mortality. Morbidity and mortality were defined as the presence of any of the following outcomes: 30-day reoperation, 30-day readmission, anastomotic leak and 30-day mortality. Characteristics investigated included: age, gender, ASA grade, BMI, presence of previous abdominal surgery, tumour distance from the anal verge, $T$ stage and neoadjuvant radiotherapy. When assessing whether high-risk patients influenced morbidity and mortality, BMI, abdominal surgery, tumour distance from the anal verge and neoadjuvant radiotherapy where not included in the analysis since these were the factors defining patients as highrisk in the study. The constant was included in the analysis model and data is presented as odds ratio (OR), 95\% confidence interval $(95 \% \mathrm{Cl})$ and $\mathrm{p}$ value.

All long-term outcomes were calculated by applying Kaplan-Meier analysis [36]. OS, DFS, distant disease-free interval and local recurrence free interval definitions were based the STEEP system published in 2007 [35]. Events included in order to calculate each long-term outcome were:

- OS: all deaths

- DFS: all deaths and disease recurrences (whether local or distal)

- distant disease-free interval: all distant recurrences 
- local recurrence free interval: all local recurrences

Statistical significance was determined by the log rank test, Breslow test or Tarone-Ware test as appropriate [37]. Maximum follow up was set to five years and median follow up time was determined by the Schemper and Smith method [38]. In this method a Kaplan-Meier analysis is performed with the event indicator reversed so that the outcome of interest is censored. This method is more robust than simply calculating the median time of follow up of all patients [39]. Univariate and multivariate Cox-regression models were applied to identify risk factors affecting OS. Outcomes assessed included: age, gender, ASA grade, BMI, presence of previous abdominal surgery, tumour distance from the anal verge, neoadjuvant radiotherapy and AJCC stage. Data is presented as hazard ratio (HR), 95\% confidence interval and $p$ value.

A subgroup analysis of the high-risk cohort was performed in order to investigate whether the number of risk factors (obesity, neoadjuvant radiotherapy, tumour $<8 \mathrm{~cm}$ from the anal verge and previous abdominal surgery) affected morbidity \& mortality and overall survival. Logistic regression and coxregression models were applied as above for this purpose.

\section{Results}

A total of 313 patients received laparoscopic rectal cancer resections, with 270 patients from the UK centre and 43 from the Portuguese centre. There was a total of 227 (72.5\%) patients in the high-risk group and $86(27.5 \%)$ in the low-risk group.

\section{Cohort characteristics}

The two cohorts were similar in terms of age, gender, operating surgeon, ASA grade and AJCC stage. In the high-risk group $35.6 \%$ of the patients were obese, $36.6 \%$ had previous abdominal surgery, $56.8 \%$ had low lying tumours and 33\% received neo-adjuvant radiotherapy. Furthermore, as expected there were differences in the procedures performed, with more abdominoperineal resections (APER) in the high-risk group. Table 1 summarises the above findings.

\section{Short-term outcomes}

The short-term surgical outcomes of the two groups are summarised in table 2. Median EBL and length of stay were longer in the high-risk group (low-risk vs high-risk: EBL 2.5 vs $10 \mathrm{ml}$; LOS 5 vs 7 days). There were no other statistically significant differences in any of the remaining investigated outcomes between the two cohorts. Conversion rate was $1.2 \%$ and $2.2 \%$ in the low and high-risk groups respectively $(p=1.000)$. There were only two 30 -day mortalities reported, both in the high-risk group 
(0.9\%), the two patients were 75 and 77 years old respectively, both received APER's and both died from myocardial infractions. Clinical anastomotic leak rate was $2.4 \%$ and $3.4 \%$ in the low and high-risk groups respectively.

\section{Logistic regression analysis for morbidity and mortality}

Univariate and multivariate regression analysis showed that high-risk patients and male gender were associated with a greater risk of morbidity and mortality (defined as the presence of any of the following outcomes: 30-day reoperation, 30-day readmission, anastomotic leak and 30-day mortality). Table 3 summarises the regression analysis for morbidity and mortality.

\section{Five-year long-term outcomes}

There was a total of 54 deaths ( 15 low-risk, 39 high-risk group) and 54 recurrences (11 low-risk, 43 high-risk group) in the examined study population. Regarding disease recurrence, there were 51 patients that suffered from distant ( 11 low risk, 40 high-risk group) and 5 from local recurrence ( 0 low risk, 5 high-risk group). Two patients had both distant and local recurrence.

There were no differences in 5 -year OS ( $79.7 \%$ vs $79.8 \%, p=0.757)$, DFS (76.8\% vs $69.3 \%, p=0.175)$, distant disease-free interval ( $84.8 \%$ vs $79.7 \%, p=0.231)$ and local recurrence free interval $(100 \%$, $97.4 \%, p=0.162$ ) between the low-risk and high-risk groups. Median follow up was 5 years for OS and DFS, 4.55 years for distant disease-free interval and 4.21 years for local recurrence free interval. Table 4 and figures 1-4 illustrate these results.

Stage by stage analysis of DFS demonstrated there were no differences between the two groups at any stage (see table 5 ).

\section{Cox-regression analysis}

In univariate cox-regression analysis for OS, age, ASA grade, neo-adjuvant radiotherapy and AJCC stage were found to affect OS, with all factors linked with a worse OS outcome. However, in multivariate cox-regression analysis age, AJCC stage and neo-adjuvant radiotherapy, but not ASA grade, were found to affect OS. Table 6 summarises the cox-regression model analysis results for OS.

\section{Number of risk factors}

In the high-risk cohort, $52 \%(n=117)$ of the patients had one of the risk factors defining them as high risk, $36.1 \%$ of the patients had two risk factors, $10.1 \%$ had three risk factors and $1.8 \%$ had all four risk factors. From the patients that only had one risk factor, 33 (28\%) were obese, $31(26 \%)$ had previous abdominal surgery, $36(31 \%)$ had tumours $<8 \mathrm{~cm}$ from the anal verge and $17(15 \%)$ received neo-adjuvant treatment. In a subgroup analysis of the high-risk cohort, the number of risk factors 
patients carried did not affect morbidity and mortality in logistic regression analysis (Univariate: OR 1.019, 95\% Cl 0.663-1.567, p=0.930; multivariate: OR 1.058, 95\% Cl 0.673-1.662, p=0.808) and did not affect overall survival in cox-regression analysis (univariate: HR 1.476, 95\% Cl 0.997-2.186, $\mathrm{p}=0.052$; multivariate: $\mathrm{HR} 1.470,95 \% \mathrm{Cl} 0.971-2.225, \mathrm{p}=0.069)$.

\section{Discussion}

Recent results from large international randomised control trials have questioned the oncological safety of laparoscopic rectal cancer surgery $[7,8]$, with these concerns being highlighted in patients with certain characteristics classifying them as high-risk. In this study we compare the short-and longterm clinical and oncological outcomes of high-risk and low-risk patients undergoing rectal MIS. We observed overall good short and long-term outcomes for both groups of patients and although the high-risk group might be associated with a higher morbidity profile, long term oncological outcomes were similar between the two groups. Our results support the hypothesis that, when standardised modular surgery and peri-operative care is applied, laparoscopic rectal cancer surgery can be safely used and offers good short and long-term results, in both low-risk and high-risk patients.

Patient characteristics influencing the surgical outcomes of colorectal resections have been extensively reported in the literature [11-24]. However, these tend to be investigated independently, such as the influence of obesity or neo-adjuvant radiotherapy on colorectal surgery [11, 12, 17-24]. There are only a few studies investigating the outcomes of high-risk patients submitted to colorectal resections [25-27]. These studies have reported good short-term outcomes for MIS in high-risk colorectal patients confirming its safety and feasibility, although the criteria used to define a case as high-risk differ between these studies [25-27]. Furthermore, two of these studies include a significant number of colonic resections (Marks et al. [25] 75\%, Hemandas et al. [26] 68\%).

Our study focused on rectal cancer and arguably represents the largest series of high-risk laparoscopic rectal resections. In addition, it presents long-term data and oncological outcomes. Interestingly, by just applying the four criteria used in our study, the majority of our patients $(72.5 \%)$ were classified as high-risk. It is important to note that there are no generally accepted definitions for high risk factors and the above studies have all used slightly different risk factor criteria.

With the exception of LOS and EBL there were no differences in the short-term clinical and pathological outcomes between the low-risk and high-risk groups. The difference in EBL ( $2.5 \mathrm{vs} 10 \mathrm{ml}$ ) is small and is unlikely to be clinically significant. In addition, considering blood loss is very difficult to accurately quantify the reported difference could be attributed to the way EBL was measured. The 
longer LOS in the high-risk group could be explained by the increased number of stomas in this group - 19\% vs 1\% APER's - and significantly more patients with low-lying tumours, all of which would have had defunctioning ileostomies. An alternative explanation to the increased length of stay observed in the high-risk group might be due to an increased morbidity profile. In further univariate regression analysis (not shown), male gender, increasing BMI and low-lying tumours conveyed a higher morbidity and mortality, with male gender and low-lying tumours continuing to be statistically significant in multivariate analysis. Therefore, it may be possible that the technical challenges encountered in the narrow male pelvis and that of tumours close to the anal verge have a negative impact on the shortterm clinical outcomes. Furthermore, ASA grade has a trend towards negatively impacting morbidity and mortality, although this did not reach statistical significance (table 3).

Of note, our reported observed pathological outcomes (surrogate features of safe oncological resection and good specimen quality) in the high-risk group support the safety and feasibility of laparoscopic surgery in this group of patients. Additionally, when comparing our results with those of the ACOSOG [7] and ALaCaRT [8] trials, conversion rate (ACOSOG: 11.3\%, ALaCaRT: 9\%) and R0 resection rate (ACOSOG: $87.7 \%$, ALaCaRT: $93 \%)$ were superior in our study (1.9\%, 96\% respectively), while mortality was similar.

We propose the potential reason for these different outcomes is that surgeries in the ACOSOG and ALaCaRT trials were performed by a wide range of surgeons and hospitals with mixed experience and volume, whereas in our study all procedures were performed in high volume centres by experienced laparoscopic surgeons, within a dedicated multidisciplinary environment. In addition, both surgeons in our study applied a reproducible, standardised approach to TME [28], while in the ACOSOG and ALaCaRT trials there was great variability in the way surgeries were conducted. We believe that by standardising operative technique and breaking down complex surgical procedures in limited extent modules, we enhance reproducibility of results and facilitate surgical training and research. This way, surgical outcomes may become fairly predictable, regardless of the surgeon or peri-operative conditions. The importance of standardising operative technique in training and producing reproducible outcomes is demonstrated in two recent publications $[40,41]$.

The reported long-term outcomes of our study confirm the oncological safety of laparoscopic surgery in high-risk rectal cancer patients. OS, DFS, distant disease-free interval and local recurrence free interval were similar between both risk groups in our study (table 4, figures 1-4). In addition, DFS was similar in a stage by stage analysis (table 5). Our observed OS and DFS in the high-risk group is comparable to that of the COREAN [6] and CLASICC [1] trials, two major trials demonstrating similar long-term oncological outcomes between laparoscopic and open rectal cancer surgery. Furthermore, 
our study replicates the recently published long term results of ACOSOG Z6051 (79.5\% DFS at 2 years) and ALaCaRT (80\% DFS and $94 \%$ OS at 2 years) trials $[9,10]$.

We acknowledge there are differences in terms of demographics and study characteristics between the discussed studies. Nevertheless, our results support the oncological safety of MIS for high-risk rectal cancers, and are at least equivalent to those of major recent trials. In cox-regression analysis age, neo-adjuvant radiotherapy and AJCC stage where found to affect OS. The fact that AJCC stage and age could affect OS is self-evident. However, the effect of neo-adjuvant radiotherapy on OS is likely to be secondary to confounding factors that have not been accounted for, since neo-adjuvant radiotherapy was only reserved for tumours that breached or threatened the CRM in our study.

The strengths of this study lie on its large sample size, the method that data was collected consecutively from two centres from two different countries, with dedicated multidisciplinary oncological teams, and its novelty in examining the long-term oncological outcomes of high-risk patients. In addition, data is contemporary, rather than data collected as part of a study that possibly includes an element of performance bias in surgical trials [42, 43]. Acknowledging its limitations, our study is retrospective in nature despite collecting data from prospectively maintained databases. Furthermore, although morbidity is assessed in this study by analysing readmission, reoperation and anastomotic leak rates; minor post-operative complications were not recorded (Clavien-Dindo 1-2). This is because minor complication data is harder to accurately record and can be easily missed. Although we acknowledge this might introduce observational bias, we know as demonstrated from previous studies published by the Cleveland group [44, 45] that readmission rate, length of stay and mortality can predict surgical morbidity, without the need to collect data for all complications.

\section{Conclusion}

In summary, our study has demonstrated that when operative technique and peri-operative care are standardised, laparoscopic rectal cancer surgery in high-risk patients is safe and offers similar shortand long-term outcomes to those of low-risk patients. Although high-risk patients might be associated with a higher morbidity profile, the observed short-term outcomes in our study confirm the suitability of laparoscopic surgery for this group of patients. We believe that in the hands of experienced surgeons, high-risk rectal cancer surgery patients should be considered for laparoscopic surgery. For these results to be validated larger scale multi-centre observational studies or trials are required. These should investigate the outcomes of high-risk rectal cancer patients receiving laparoscopic rectal cancer surgery by a standardised operative technique and peri-operative care pathway. 


\section{Compliance with Ethical Standards}

\section{Disclosure of potential conflicts of interest}

Mr S Panteleimonitis, Dr N Figueiredo, Ms T Bhunakrishna, Dr M Harper and Prof A Parvaiz have no conflicts of interest or financial ties to disclose.

\section{Research involving Human Participants and/or Animals}

All procedures performed in studies involving human participants were in accordance with the ethical standards of the institutional and/or national research committee and with the 1964 Helsinki declaration and its later amendments or comparable ethical standards. For this type of study formal consent is not required.

Informed consent

Informed verbal consent was obtained from all individual participants included in the study.

\section{Acknowledgements}

We would like to thank Karen Flashman for all her help in maintaining the colorectal surgery database in Queen Alexandra Hospital, Portsmouth. 


\section{References}

1. Jayne DG, Thorpe HC, Copeland J, et al (2010) Five-year follow-up of the Medical Research Council CLASICC trial of laparoscopically assisted versus open surgery for colorectal cancer. $\mathrm{Br}$ J Surg 97:1638-1645. doi: 10.1002/bjs.7160

2. Kennedy RH, Francis EA, Wharton R, et al (2014) Multicenter randomized controlled trial of conventional versus laparoscopic surgery for colorectal cancer within an enhanced recovery programme: EnROL. J Clin Oncol 32:1804-1811. doi: 10.1200/JCO.2013.54.3694

3. Veldkamp R, Kuhry E, Hop WC, et al (2005) Laparoscopic surgery versus open surgery for colon cancer: short-term outcomes of a randomised trial. Lancet Oncol 6:477-484. doi: 10.1016/s1470-2045(05)70221-7

4. van der Pas MH, Haglind E, Cuesta MA, et al (2013) Laparoscopic versus open surgery for rectal cancer (COLOR II): short-term outcomes of a randomised, phase 3 trial. Lancet Oncol 14:210-8. doi: 10.1016/S1470-2045(13)70016-0

5. Kang S-BB, Park JW, Jeong S-YY, et al (2010) Open versus laparoscopic surgery for mid or low rectal cancer after neoadjuvant chemoradiotherapy (COREAN trial): Short-term outcomes of an open-label randomised controlled trial. Lancet Oncol 11:637-645. doi: 10.1016/S14702045(10)70131-5

6. Jeong S-YY, Park JW, Nam BH, et al (2014) Open versus laparoscopic surgery for mid-rectal or low-rectal cancer after neoadjuvant chemoradiotherapy (COREAN trial): Survival outcomes of an open-label, non-inferiority, randomised controlled trial. Lancet Oncol 15:767-774. doi: 10.1016/S1470-2045(14)70205-0

7. Fleshman J, Branda M, Sargent DJ, et al (2015) Effect of Laparoscopic-Assisted Resection vs Open Resection of Stage II or III Rectal Cancer on Pathologic Outcomes: The ACOSOG Z6051 Randomized Clinical Trial. Jama 314:1346-1355. doi: 10.1001/jama.2015.10529

8. Stevenson ARL, Solomon MJ, Lumley JW, et al (2015) Effect of Laparoscopic-Assisted Resection vs Open Resection on Pathological Outcomes in Rectal Cancer: The ALaCaRT Randomized Clinical Trial. Jama 314:1356-1363. doi: 10.1001/jama.2015.12009

9. Stevenson ARL, Solomon MJ, Brown CSB, et al (2018) Disease-free Survival and Local Recurrence After Laparoscopic-assisted Resection or Open Resection for Rectal Cancer: The Australasian Laparoscopic Cancer of the Rectum Randomized Clinical Trial. Ann Surg. doi: 10.1097/SLA.0000000000003021

10. Fleshman J, Branda ME, Sargent DJ, et al (2018) Disease-free Survival and Local Recurrence for Laparoscopic Resection Compared With Open Resection of Stage II to III Rectal Cancer: Follow-up Results of the ACOSOG Z6051 Randomized Controlled Trial. Ann Surg. doi: 10.1097/SLA.0000000000003002

11. He Y, Wang J, Bian H, et al (2017) BMI as a Predictor for Perioperative Outcome of Laparoscopic Colorectal Surgery: A Pooled Analysis of Comparative Studies. Dis Colon Rectum 60:433-445. doi: 10.1097/DCR.0000000000000760

12. Fung A, Trabulsi N, Morris M, et al (2017) Laparoscopic colorectal cancer resections in the obese: a systematic review. Surg Endosc Other Interv Tech 31:2072-2088. doi: 10.1007/s00464-016-5209-y

13. Chand M, Bhoday J, Brown G, et al (2012) Laparoscopic surgery for rectal cancer. J R Soc Med 105:429-435. doi: 10.1258/jrsm.2012.120070 
14. Franko J, O'Connell BG, Mehall JR, et al (2006) The influence of prior abdominal operations on conversion and complication rates in laparoscopic colorectal surgery. JSLS J Soc Laparoendosc Surg 10:169-175.

15. Ishihara S, Watanabe T, Fukushima $Y$, et al (2014) Safety and factors contributing to the difficulty of laparoscopic surgery for rectal cancer treated with preoperative chemoradiotherapy. Tech Coloproctol 18:247-255. doi: 10.1007/s10151-013-1048-1

16. Akiyoshi T, Kuroyanagi $\mathrm{H}$, Oya $\mathrm{M}$, et al (2009) Factors affecting the difficulty of laparoscopic total mesorectal excision with double stapling technique anastomosis for low rectal cancer. Surgery 146:483-489. doi: 10.1016/j.surg.2009.03.030

17. Yang T, Wei M, He Y, et al (2015) Impact of visceral obesity on outcomes of laparoscopic colorectal surgery: A meta-analysis. ANZ J Surg 85:507-513. doi: 10.1111/ans.13132

18. Hotouras a., Ribas $Y$, Zakeri $S$ a., et al (2016) The influence of obesity and body mass index on the outcome of laparoscopic colorectal surgery: a systematic literature review. Color Dis 18:0337-0366. doi: 10.1111/codi.13406

19. Khoury W, Kiran RP, Jessie T, et al (2010) Is the laparoscopic approach to colectomy safe for the morbidly obese? Surg Endosc Other Interv Tech 24:1336-1340. doi: 10.1007/s00464-009$0770-2$

20. Lee W-S, Yun SH, Roh Y-N, et al (2008) Risk factors and clinical outcome for anastomotic leakage after total mesorectal excision for rectal cancer. World J Surg 32:1124-1129. doi: $10.1007 / \mathrm{s} 00268-007-9451-2$

21. Lyall A, Mc Adam TK, Townend J, Loudon MA (2007) Factors affecting anastomotic complications following anterior resection in rectal cancer. Colorectal Dis 9:801-807. doi: 10.1111/j.1463-1318.2006.01197.x

22. Marijnen CAM, Kapiteijn E, van de Velde CJH, et al (2002) Acute side effects and complications after short-term preoperative radiotherapy combined with total mesorectal excision in primary rectal cancer: report of a multicenter randomized trial. J Clin Oncol 20:817-825. doi: 10.1200/JCO.2002.20.3.817

23. Goldberg PA, Nicholls RJ, Porter NH, et al (1994) Long-term results of a randomised trial of short-course low-dose adjuvant pre-operative radiotherapy for rectal cancer: reduction in local treatment failure. Eur J Cancer 30A:1602-1606.

24. (1990) Preoperative short-term radiation therapy in operable rectal carcinoma. A prospective randomized trial. Stockholm Rectal Cancer Study Group. Cancer 66:49-55.

25. Marks JH, Kawun UB, Hamdan W, Marks G (2008) Redefining contraindications to laparoscopic colorectal resection for high-risk patients. Surg Endosc 22:1899-1904. doi: 10.1007/s00464-008-9828-9

26. Hemandas AK, Abdelrahman T, Flashman KG, et al (2010) Laparoscopic colorectal surgery produces better outcomes for high risk cancer patients compared to open surgery. Ann Surg 252:84-89. doi: 10.1097/SLA.0b013e3181e45b66

27. Ahmed J, Cao H, Panteleimonitis S, et al (2017) Robotic versus laparoscopic rectal surgery in high-risk patients. Colorectal Dis. doi: 10.1111/codi.13783

28. Miskovic D, Foster J, Agha A, et al (2015) Standardization of laparoscopic total mesorectal excision for rectal cancer: a structured international expert consensus. Ann Surg 261:716722. doi: $10.1097 /$ SLA.0000000000000823

29. Hemandas A, Flashman KG, Farrow J, et al (2011) Modular training in laparoscopic colorectal surgery maximizes training opportunities without clinical compromise. World J Surg 35:409- 
414. doi: $10.1007 / \mathrm{s} 00268-010-0837-1$

30. Ahmed J, Panteleimonitis S, Parvaiz A (2016) Modular approach for single docking robotic colorectal surgery. J Vis Surg 2:109-109. doi: 10.21037/jovs.2016.06.07

31. Kehlet H, Wilmore DW (2002) Multimodal strategies to improve surgical outcome. Am J Surg 183:630-641.

32. Coleman M, Cecil T (2017) Laparoscopic Colorectal Surgery The Lapco Manual. CRC Pr I Llc

33. Popeskou S-G, Panteleimonitis S, Christoforidis D, et al (2017) Port Placement for Laparoscopic Colonic Resections - Video Vignette. Colorectal Dis. doi: 10.1111/codi.13974

34. Ahmed J, Kuzu MA, Figueiredo N, et al (2016) Three-step standardised approach for complete mobilisation of the splenic flexure during robotic rectal cancer surgery. Colorectal Dis 171174. doi: $10.1111 /$ codi.13313

35. Hudis CA, Barlow WE, Costantino JP, et al (2007) Proposal for standardized definitions for efficacy end points in adjuvant breast cancer trials: The STEEP system. J Clin Oncol 25:21272132. doi: $10.1200 / J C O .2006 .10 .3523$

36. Kaplan EL, Meier P (1958) Nonparametric Estimation from Incomplete Observations. J Am Stat Assoc 53:457-481. doi: 10.1080/01621459.1958.10501452

37. Peto R, Peto J (1972) Asymptotically Efficient Rank Invariant Test Procedures. J R Stat Soc Ser A 135:185-207. doi: 10.2307/2344317

38. Schemper M, Smith TL (1996) A note on quantifying follow-up in studies of failure time. Control Clin Trials 17:343-346.

39. Clark TG, Bradburn MJ, Love SB, Altman DG (2003) Survival analysis part I: basic concepts and first analyses. Br J Cancer 89:232-238. doi: 10.1038/sj.bjc.6601118

40. Panteleimonitis S, Popeskou S, Aradaib M, et al (2018) Implementation of robotic rectal surgery training programme: importance of standardisation and structured training.

Langenbeck's Arch Surg. doi: 10.1007/s00423-018-1690-1

41. Bullock M, Nasir IUI, Hemandas A, et al (2019) Standardised approach to laparoscopic total mesorectal excision for rectal cancer: a prospective multi-centre analysis. Langenbeck's Arch Surg 404:547-555. doi: 10.1007/s00423-019-01806-w

42. McCulloch P, Taylor I, Sasako M, et al (2002) Randomised trials in surgery: problems and possible solutions. Bmj 324:1448-1451. doi: 10.1136/bmj.324.7351.1448

43. Bothwell LE, Greene JA, Podolsky SH, Jones DS (2016) Assessing the Gold Standard--Lessons from the History of RCTs. N Engl J Med 374:2175-2181. doi: 10.1056/NEJMms1604593

44. Crawshaw BP, Keller DS, Brady JT, et al (2017) The HARM score for gastrointestinal surgery: Application and validation of a novel, reliable and simple tool to measure surgical quality and outcomes. Am J Surg 213:575-578. doi: 10.1016/j.amjsurg.2016.11.007

45. Keller DS, Chien H-L, Hashemi L, et al (2014) The HARM score: a novel, easy measure to evaluate quality and outcomes in colorectal surgery. Ann Surg 259:1119-1125. doi:

10.1097/SLA.0b013e3182a6f45e 


\section{Tables}

Table 1. Baseline characteristics of low-risk vs high-risk patients

\begin{tabular}{|c|c|c|c|}
\hline & Low risk $(n=86)$ & High risk $(n=227)$ & $P$ value \\
\hline Age & $66.7(60.8-74.3)$ & $66(59.4-75)$ & $.893 m$ \\
\hline $\begin{array}{l}\text { Gender } \\
\text { - Male } \\
\text { - female }\end{array}$ & $\begin{array}{l}57(66.3 \%) \\
29(33.7 \%)\end{array}$ & $\begin{array}{l}137(60.4 \%) \\
90(39.6 \%)\end{array}$ & $.363 c$ \\
\hline Median BMI & $25.9(24-27)$ & $27.2(24-31)$ & $.000 \mathrm{~m}$ \\
\hline Obese* & 0 & $80(35.6 \%)$ & $.000 f$ \\
\hline $\begin{array}{c}\text { ASA grade } \\
\begin{aligned}- & 1 \\
- & 2 \\
- & 3 \\
- & 4\end{aligned}\end{array}$ & $\begin{array}{l}14(16.3 \%) \\
55(64 \%) \\
16(18.6 \%) \\
1(1.2 \%)\end{array}$ & $\begin{array}{l}19(8.6 \%) \\
153(69.2 \%) \\
48(21.7 \%) \\
1(0.5 \%)\end{array}$ & $.219 c$ \\
\hline $\begin{array}{l}\text { Previous abdominal } \\
\text { surgery* }\end{array}$ & 0 & $83(36.6 \%)$ & $.000 f$ \\
\hline $\begin{array}{l}\text { Median distance from } \\
\text { anal verge in } \mathrm{cm}\end{array}$ & $10(10-14)$ & $7(5-10)$ & $.000 \mathrm{~m}$ \\
\hline Low tumour $(<8 \mathrm{~cm}) *$ & 0 & $129(56.8 \%)$ & $.000 f$ \\
\hline $\begin{array}{l}\text { Neoadjuvant } \\
\text { radiotherapy* }\end{array}$ & 0 & $75(33 \%)$ & $.000 f$ \\
\hline $\begin{array}{ll}\text { Procedure } \\
\text { - } \\
\quad \text { Anterior } \\
\text { - } \text { resection } \\
\text { - } \text { APER } \\
\text { - } \text { other }\end{array}$ & $\begin{array}{l}82(95.3 \%) \\
1(1.2 \%) \\
2(2.3 \%) \\
1(1.2 \%)\end{array}$ & $\begin{array}{l}177(78 \%) \\
44(19.4 \%) \\
3(1.3 \%) \\
3(1.3 \%)\end{array}$ & $.001 c$ \\
\hline $\begin{aligned} \text { AJCC stage } \\
\begin{aligned}- & 1 \\
- & 2 \\
- & 3 \\
- & 4\end{aligned}\end{aligned}$ & $\begin{array}{l}29(33.7 \%) \\
22(25.6 \%) \\
31(36.0 \%) \\
4(4.7 \%)\end{array}$ & $\begin{array}{l}89(39.2 \%) \\
61(26.9 \%) \\
63(27.8 \%) \\
14(6.2 \%)\end{array}$ & $.529 c$ \\
\hline
\end{tabular}

*criteria for high risk

APER: Abdominoperineal excision; m: Mann-Whitney U; c: Chi square; f: Fisher's exact 
Table 2. Short term clinical and pathological outcomes of low-risk vs high-risk patients

\begin{tabular}{|l|l|l|l|}
\hline $\begin{array}{l}\text { Median operation time } \\
\text { in min }\end{array}$ & Low-risk & High-risk & P value \\
\hline $\begin{array}{l}\text { Median estimated blood } \\
\text { loss in ml }\end{array}$ & $215(186.3-250)$ & $220(205-255)$ & $0.091 \mathrm{~m}$ \\
\hline Conversion & $1(1.2 \%)$ & $10(0-40)$ & $0.045 \mathrm{~m}^{*}$ \\
\hline Median LOS in days & $5(4-8)$ & $5(2.2 \%)$ & $1.000 \mathrm{f}$ \\
\hline 30-day mortality & 0 & $7(5-11)$ & $0.001 \mathrm{~m}^{*}$ \\
\hline 30-day readmission & $9(10.5 \%)$ & $2(0.9 \%)$ & $1.000 \mathrm{f}$ \\
\hline 30-day reoperation & $2(2.3 \%)$ & $37(16.3 \%)$ & $0.193 \mathrm{c}$ \\
\hline Anastomotic leak & $2(2.4 \%)$ & $9(4 \%)$ & $0.733 \mathrm{f}$ \\
\hline CRM (R0) & $83(96.5 \%)$ & $218(96 \%)$ & $1.000 \mathrm{f}$ \\
\hline Lymph node yield & $13(8-19.5)$ & $15(10-21)$ & $0.673 \mathrm{c}$ \\
\hline
\end{tabular}

LOS: length of stay; CRM: circumferential resection margin; m: Mann-Whitney U; f: Fisher's exact; c: Chi square; * statistically significant

Table 3. Univariate and multivariate logistic regression investigating the effect of high-risk on morbidity and mortality

\begin{tabular}{|l|l|l|l|l|l|l|}
\hline & \multicolumn{3}{l}{ Univariate } & \multicolumn{2}{l|}{ Multivariate } \\
\hline & OR & $95 \% \mathrm{Cl}$ & $p$ value & OR & $95 \% \mathrm{Cl}$ & $p$ value \\
\hline High risk & 2.294 & $1.073-4.908$ & $0.032^{*}$ & 2.321 & $1.072-5.023$ & $0.033^{*}$ \\
\hline age & 0.994 & $0.969-1.019$ & 0.630 & 0.986 & $0.958-1.015$ & 0.341 \\
\hline Male gender & 2.136 & $1.112-4.101$ & $0.023^{*}$ & 2.121 & $1.082-4.161$ & $0.02{ }^{*}$ \\
\hline ASA grade & 1.653 & $0.998-2.739$ & 0.051 & 1.745 & $0.992-3.071$ & 0.053 \\
\hline T stage & 1.036 & $0.744-1.442$ & 0.835 & 0.997 & $0.697-1.427$ & 0.987 \\
\hline
\end{tabular}

OR: odds ratio; $\mathrm{Cl}$ : confidence interval; * statistically significant

Table 4. Five-year long-term outcomes of laparoscopic rectal cancer resections

\begin{tabular}{|l|l|l|l|l|}
\hline & Low-risk & High-risk & $\boldsymbol{p}$ value & Median follow up \\
\hline OS & $79.7 \%$ & $79.8 \%$ & 0.757 & 5 years \\
\hline DFS & $76.8 \%$ & $69.3 \%$ & 0.175 & 5 years \\
\hline $\begin{array}{l}\text { Distant disease- } \\
\text { free interval }\end{array}$ & $84.8 \%$ & $79.7 \%$ & 0.231 & 4.55 years \\
\hline $\begin{array}{l}\text { Local recurrence } \\
\text { free interval }\end{array}$ & $100 \%$ & $97.4 \%$ & 0.162 & 4.21 years \\
\hline
\end{tabular}

OS: overall survival; DFS: disease-free survival 
Table 5. Five-year disease-free survival by American Joint Committee on Cancer (AJCC) stage

\begin{tabular}{|l|l|l|l|l|}
\hline AJCC stage & Low-risk & High-risk & $\boldsymbol{p}$ value & Median follow up \\
\hline $\mathbf{1}$ & $90.9 \%$ & $82.4 \%$ & 0.311 & 4.81 years \\
\hline $\mathbf{2}$ & $81.1 \%$ & $67 \%$ & 0.254 & 5.00 years \\
\hline $\mathbf{3}$ & $64.6 \%$ & $64.9 \%$ & 0.764 & 5.00 years \\
\hline
\end{tabular}

AJCC: American Joint Committee on Cancer

Table 6. Univariate and multivariate Cox-regression analysis for overall survival

\begin{tabular}{|c|c|c|c|c|c|c|c|c|c|c|}
\hline \multirow[b]{3}{*}{ age } & \multicolumn{5}{|c|}{ Univariate } & \multicolumn{5}{|c|}{ Multivariate } \\
\hline & \multirow{2}{*}{$\begin{array}{l}\text { HR } \\
1.064\end{array}$} & \multicolumn{3}{|c|}{$95 \% \mathrm{Cl}$} & \multirow{2}{*}{$\begin{array}{l}p \text { value } \\
.000 *\end{array}$} & \multirow{2}{*}{$\begin{array}{l}\text { HR } \\
1.061\end{array}$} & \multicolumn{3}{|c|}{$95 \% \mathrm{Cl}$} & \multirow{2}{*}{$\begin{array}{l}p \text { value } \\
.000 *\end{array}$} \\
\hline & & 1.036 & - & 1.092 & & & 1.029 & - & 1.094 & \\
\hline Male gender & .958 & .554 & - & 1.656 & .878 & .902 & .510 & - & 1.593 & .722 \\
\hline BMI & .944 & .885 & - & 1.008 & .084 & .987 & .921 & - & 1.058 & .717 \\
\hline ASA grade & 1.674 & 1.053 & - & 2.662 & $.029 *$ & 1.261 & .736 & - & 2.163 & .399 \\
\hline $\begin{array}{l}\text { No previous } \\
\text { abdominal } \\
\text { surgery }\end{array}$ & .973 & .903 & - & 1.875 & .949 & .954 & .505 & - & 1.801 & .884 \\
\hline $\begin{array}{l}\text { Anal verge } \\
\text { distance }\end{array}$ & .973 & .903 & - & 1.049 & .473 & 1.010 & .924 & - & 1.104 & .831 \\
\hline $\begin{array}{l}\text { No neo- } \\
\text { adjuvant } \\
\text { radiotherapy }\end{array}$ & .398 & .230 & - & .688 & $.001^{*}$ & .443 & .232 & - & .848 & $.014^{*}$ \\
\hline AJCC stage & 1.912 & 1.439 & - & 2.541 & $.000^{*}$ & 1.864 & 1.370 & - & 2.535 & $.000 *$ \\
\hline
\end{tabular}

HR: hazard ratio; 95\% Cl: 95\% confidence interval; * statistically significant 


\section{Figures legends}

Fig. 1. Overall survival for high-risk vs low-risk laparoscopic rectal resections

Fig. 2. Disease free survival for high-risk vs low-risk laparoscopic rectal resections

Fig. 3. Distant disease-free survival for high-risk vs low-risk laparoscopic rectal resections

Fig. 4. Local recurrence free interval for high-risk vs low-risk laparoscopic rectal resections

Fig. 5. Disease free survival by AJCC stage for high-risk vs low-risk laparoscopic rectal resections

Figures

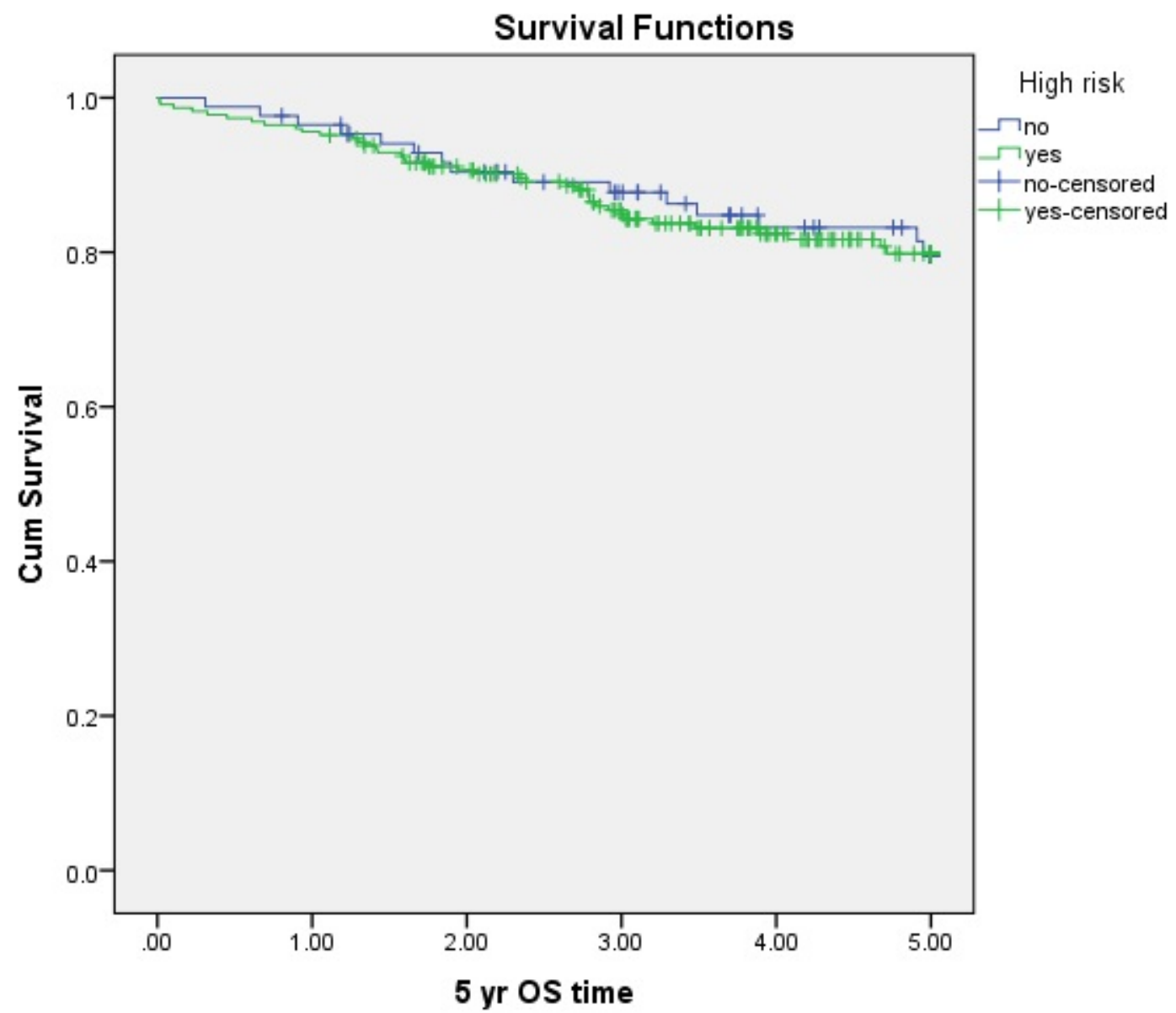

Figure 1 


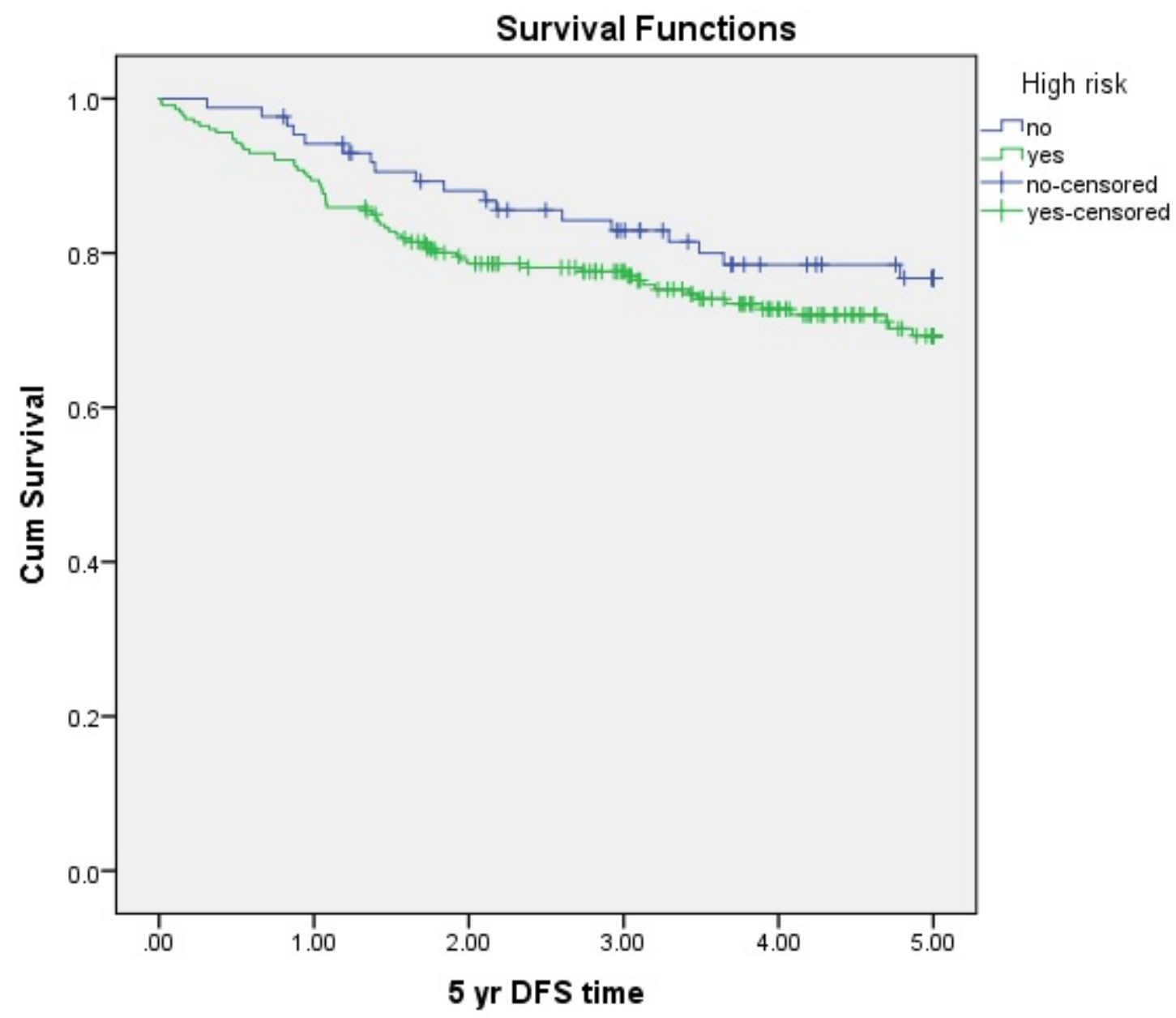

Figure 2 


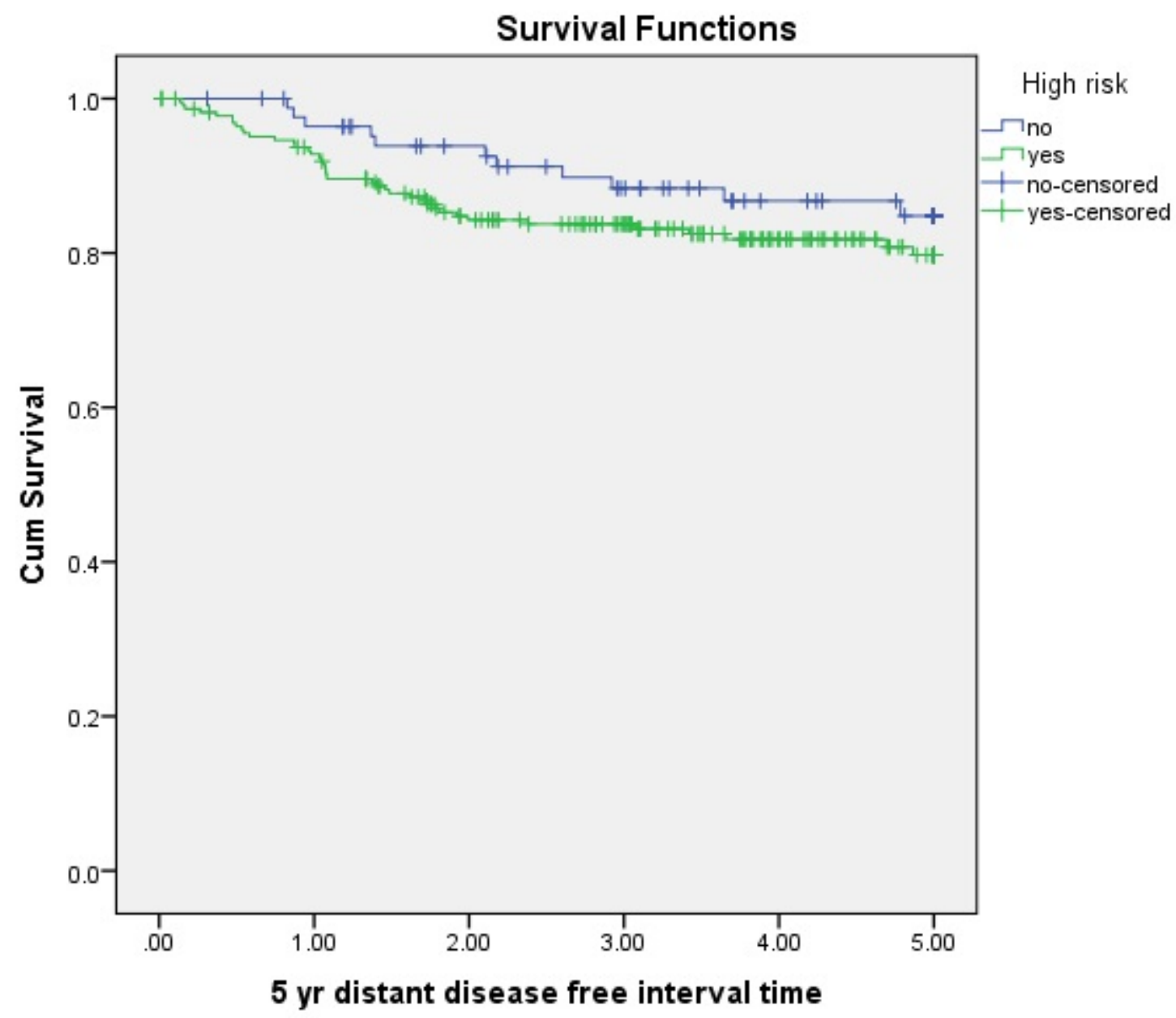

Figure 3 


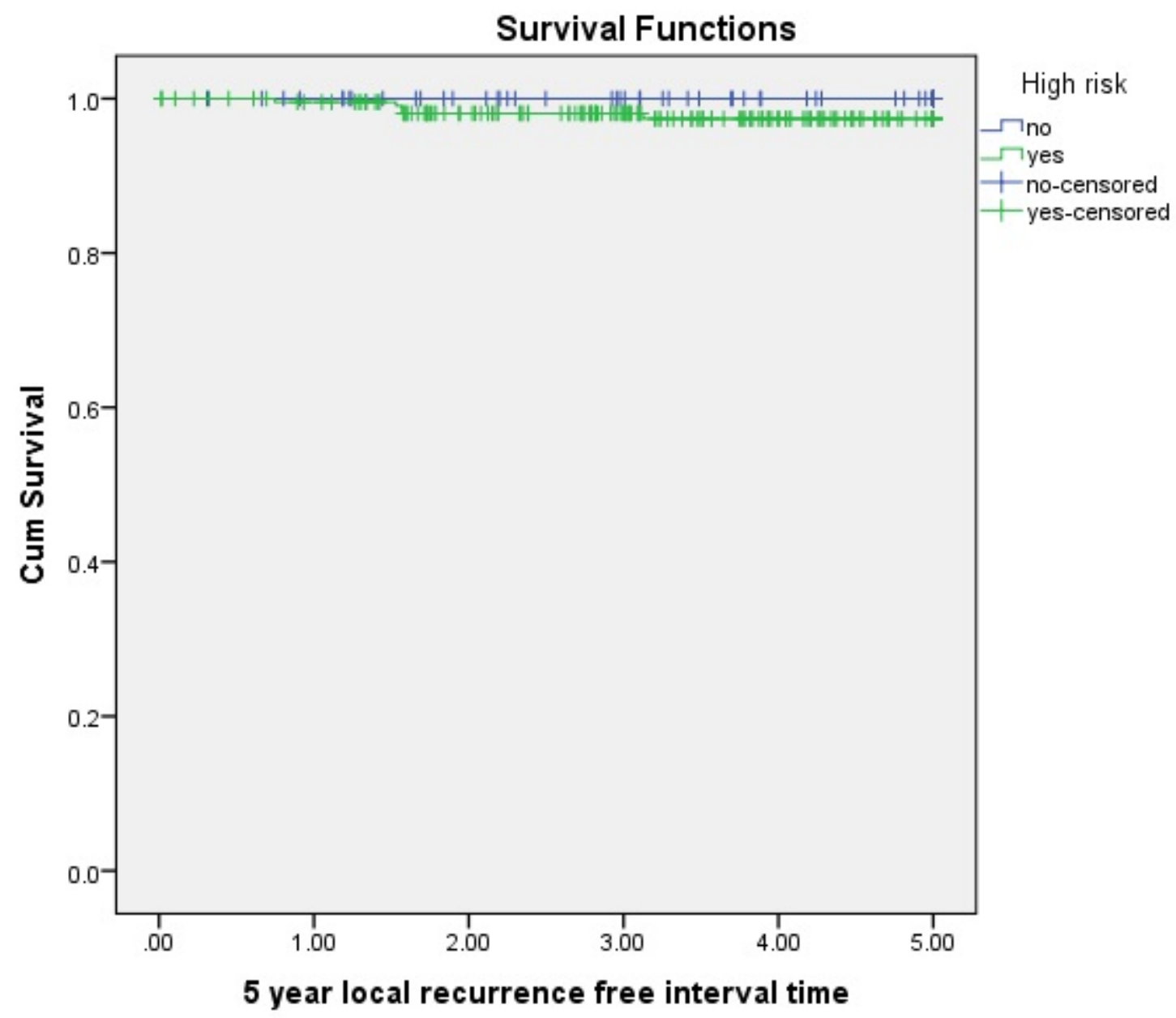

Figure 4 

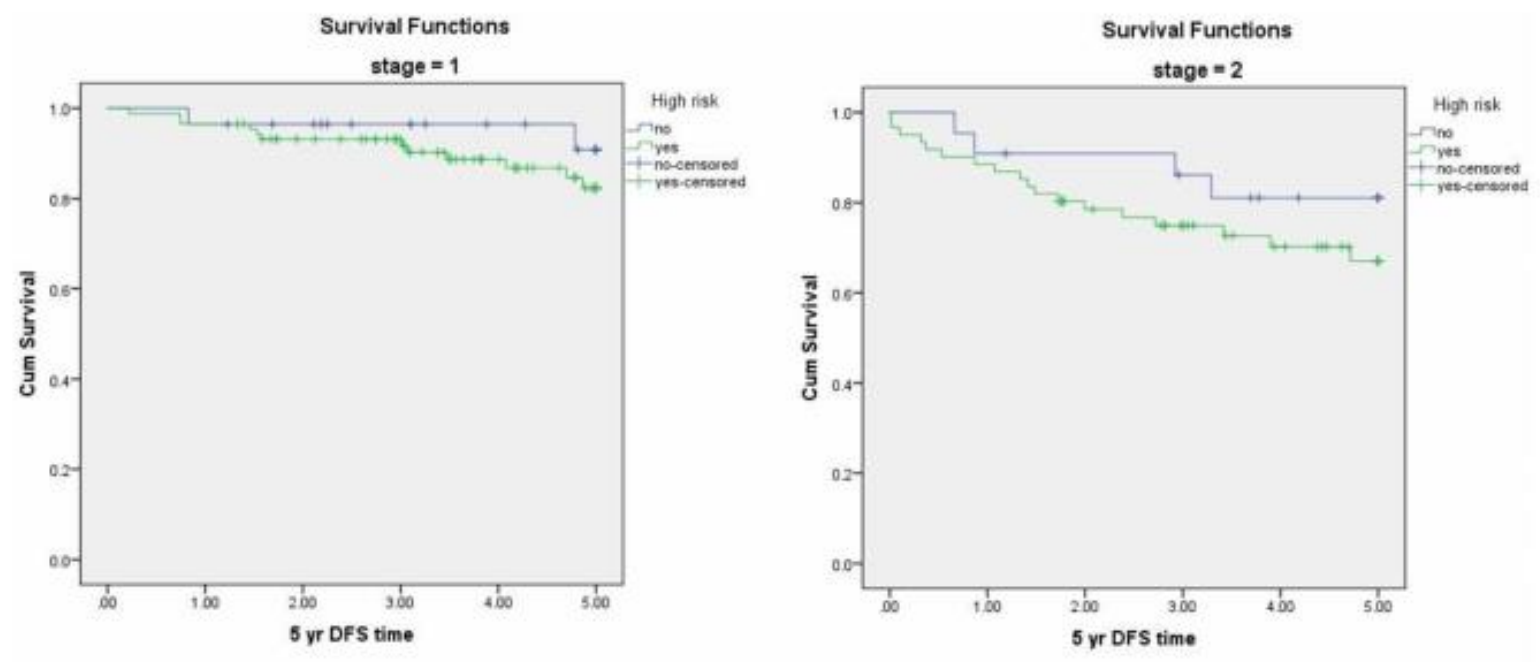

Survival Functions

stage $=3$

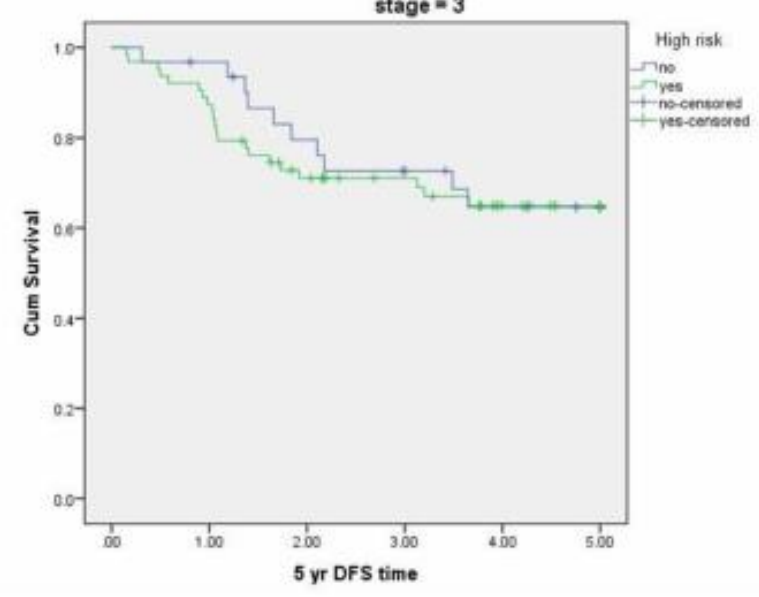

Figure 5 